\title{
Continuous decolourization of a sugar refinery wastewater in a modified rotating biological contactor with Phanerochaete chrysosporium immobilized on polyurethane foam disks
}

\author{
C. Guimarães ${ }^{\mathrm{a}, \mathrm{b}}$, P. Porto ${ }^{\mathrm{a}}$, R. Oliveira ${ }^{\mathrm{b}}$, M. Mota ${ }^{\mathrm{b}, *}$ \\ a DID-Sugar Research Department, RAR—Refinarias de Açúcar Reunidas S.A., Porto, Portugal \\ ${ }^{\mathrm{b}}$ Centro de Engenharia Biológica, IBQF, Universidade do Minho, Campus de Gualtar 4710-057, Braga Codex, Portugal
}

Received 10 June 2003; received in revised form 23 October 2003; accepted 19 November 2003

\begin{abstract}
Phanerochaete chrysosporium immobilized on different support materials, such as polyurethane foam (PUF) and scouring web (SW), in shake cultures, was able to decolourize efficiently the sugar refinery effluent in a long-term repeated-batch operation. The decolourization medium composition was optimized using PUF-immobilized fungus. Addition of glucose was obligatory and the minimum glucose concentration was found to be $5 \mathrm{~g} / \mathrm{l}$. A rotating biological contactor (RBC) containing P. chrysosporium immobilized on PUF disks was operated with optimized decolourization medium, in continuous mode with a retention time of 3 days. By simply reversing the feed inlet of the reactor, after 17 days of operation, it was possible to double the active fungal lifetime. During the course of operation the colour, total phenols and chemical oxygen demand were reduced by 55,63 and $48 \%$, respectively.
\end{abstract}

(c) 2003 Elsevier Ltd. All rights reserved.

Keywords: Decolourization; Sugar refinery effluent; Melanoidin; Phanerochaete chrysosporium; Rotating biological contactor

\section{Introduction}

Sugar refineries generate a highly coloured effluent resulting from the regeneration of anion-exchange resins (used to decolourize sugar liquor) [1]. This effluent represents an environmental problem due to its high organic load, intense colouration and presence of phenolic compounds. The coloured nature of the effluent is mainly due to (1) the presence of melanoidins, that are brown polymers formed by the Maillard amino-carbonyl reaction and (2) the presence of thermal and alkaline degradation products of sugars (e.g. caramels) [2]. Most of the organic matter present in the effluent can be reduced by conventional biological treatments but the colour is hardly removed by these treatments $[3,4]$. The remaining colour can lead to a reduction of sunlight penetration in rivers and streams which in turn decreases both photosynthetic activity and dissolved oxygen concentrations causing harm to aquatic life.

\footnotetext{
* Corresponding author. Tel.: +351-2-53604400; fax: +351-2-53678986.

E-mail address: mmota@deb.uminho.pt (M. Mota).
}

Physico-chemical treatments to remove colour have high operational costs and a limited applicability, which render these techniques unattractive [5].

White-rot fungi have been reported to be capable of decolourizing melanoidin containing wastewaters [3,6-8]. Previous studies showed that the white-rot fungus Phanerochaete chrysosporium can remove colour and total phenols from the sugar refinery effluent [9].

In order to achieve an effective continuous wastewater treatment with $P$. chrysosporium, a bioreactor has to be developed in which the fungal cells can grow well while keeping the effluent degrading activity for long periods. There are few reports specifically on melanoidin-containing wastewater decolourization in bioreactors with white-rot fungi. Ohmomo et al. [10] reported the continuous decolourization of molasses wastewater in a bubbling column reactor with Coriolus versicolor immobilized within Ca-alginate gel. Recently, Fujita et al. [8] also considered the decolourization of melanoidin present in an effluent, using a bioreactor with Coriolus hirsutus immobilized onto polyurethane foam cubes. The aim of this study was to find a suitable industrial biological treatment process for efficient decolourization of sugar refinery effluent. 
The rotating biological contactor (RBC) is a proven technology for large-scale wastewater treatment applications, offering several advantages: low-shear environment, easy scale-up, high surface area per unit volume, low maintenance costs, low energy requirements, simple construction and operation [11]. The use of polyurethane foam (PUF) was found to be an emerging technology for biological wastewater treatment by the Environmental Protection Agency (US EPA) [12].

Considering the previous comments, a modified RBC with polyurethane foam attached to the disks, to increase the area for $P$. chrysosporium immobilization, was investigated to assess the possibility of continuous treatment of sugar refinery effluent.

\section{Materials and methods}

\subsection{Microorganism and inoculum}

The inoculum consisted of a suspension of homogenized P. chrysosporium (ATCC 24725) mycelium, grown in liquid culture for $48 \mathrm{~h}$ [13].

\subsection{Effluent}

The effluent was collected in the sugar refinery RARRefinarias de Açúcar Reunidas S.A., Porto, Portugal, and stored at $4{ }^{\circ} \mathrm{C}$ until used.

\subsection{Culture medium}

Unless otherwise indicated, the basal decolourization medium consisted of sugar refinery effluent (adjusted to $\mathrm{pH}$ 4.5 with $\mathrm{HCl}$ ) supplemented with (final composition per litre): $5 \mathrm{~g}$ glucose; $2.0 \mathrm{~g} \mathrm{KH} \mathrm{PO}_{4} ; 1.06 \mathrm{~g} \mathrm{MgSO}_{4} \cdot 7 \mathrm{H}_{2} \mathrm{O}$; $0.032 \mathrm{~g} \mathrm{NH}_{4} \mathrm{Cl} ; 10 \mathrm{ml}$ mineral solution and $10 \mathrm{ml}$ thiamine solution $(100 \mathrm{mg} / \mathrm{l})$ and was sterilized by filtration $(0.45 \mu \mathrm{m})$. The mineral solution composition is described elsewhere [9]. The growth medium used in the repeated-batch experiments for carrier selection, was identical to the basal decolourization medium but contained $10 \mathrm{~g} / \mathrm{l}$ glucose and $0.128 \mathrm{~g} / \mathrm{l} \mathrm{NH}{ }_{4} \mathrm{Cl}$. Growth medium devoid of effluent was used in the experiments for optimization of decolourization medium composition and in the continuous treatment with RBC.

\subsection{Repeated-batch decolourization experiments}

The immobilization of $P$. chrysosporium on the support particles was carried out in $500 \mathrm{ml}$ serum bottles containing $18 \mathrm{ml}$ support and $24 \mathrm{ml}$ growth medium inoculated with $10 \%(\mathrm{v} / \mathrm{v})$ inoculum, under orbital agitation at $100 \mathrm{rpm}$ and $38^{\circ} \mathrm{C}$, until the supports were completely colonized. After immobilization, the medium was withdrawn and replaced with decolourization medium. The medium was changed at specific time intervals under the same conditions for repeated-batch decolourization tests. The serum bottles were aerated everyday with pure oxygen $(2 \mathrm{l} / \mathrm{min}$ ) for $3 \mathrm{~min}$. Samples were routinely taken for analysis. The support materials tested were polyurethane foam and scouring web (Scotch-Brite, 3M Company, Spain) cut into approximately cubic pieces $(5 \mathrm{~mm} \times 5 \mathrm{~mm} \times 7 \mathrm{~mm})$.

\section{5. $R B C$ reactor studies}

The closed RBC was constructed from a polymethylmethacrylate cylinder, $25 \mathrm{~cm}$ in length and $18 \mathrm{~cm}$ in diameter. The main chamber of the reactor was divided into three identical stages, each composed of three disks of $14 \mathrm{~cm}$ diameter. A layer of polyurethane foam (PUF) of $2.5 \mathrm{~mm}$ thickness was attached on both sides of each plastic disk. The disks were mounted on a horizontal steel shaft and rotated at $4 \mathrm{rpm}$. During operation the disks were $40 \%$ submerged. The reactor had a working volume of 1.51 . The atmosphere was enriched by introducing a continuous flow $(40 \mathrm{ml} / \mathrm{min})$ of pure oxygen. The temperature was maintained at $38^{\circ} \mathrm{C}$ by means of a heating jacket.

Experiments were started in batch mode to immobilize fungal biomass onto the disks. 1.51 of growth medium was sterilized and placed in the RBC reactor, inoculated with $10 \%(\mathrm{v} / \mathrm{v})$ inoculum and then operated for 4 days. After immobilization, the growth medium was removed and the decolourization medium was continuously fed into the reactor at a flow rate of $0.35 \mathrm{ml} / \mathrm{min}$ (hydraulic retention time of 3 days).

\subsection{Analytical procedures}

Colour was measured at $420 \mathrm{~nm}$ after $\mathrm{pH}$ adjustment to $\mathrm{pH} 9.0$ with $0.012 \mathrm{M}$ borate buffer. Total phenols were determined using the Folin and Ciocalteau reagent, based on the method described by Singleton and Rossi [14]. The chemical oxygen demand (COD) was determined according to the closed reflux colorimetric method [15]. An HACH COD digestion system and a spectrophotometer HACH-2000 were employed. The proportion of the total COD derived from sugar refinery effluent was calculated by subtracting the COD of added glucose from the total COD. Glucose concentration was measured by using an enzymatic Boehringer-Mannheim/716251 Kit.

\section{Results and discussion}

\subsection{Repeated-batch decolourization tests (carrier selection)}

The longevity of the decolourization activity of $P$. chrysosporium immobilized on two different carriers previously selected [16], polyurethane foam (PUF) and scouring web (SW), was measured in repeated-batch tests. 


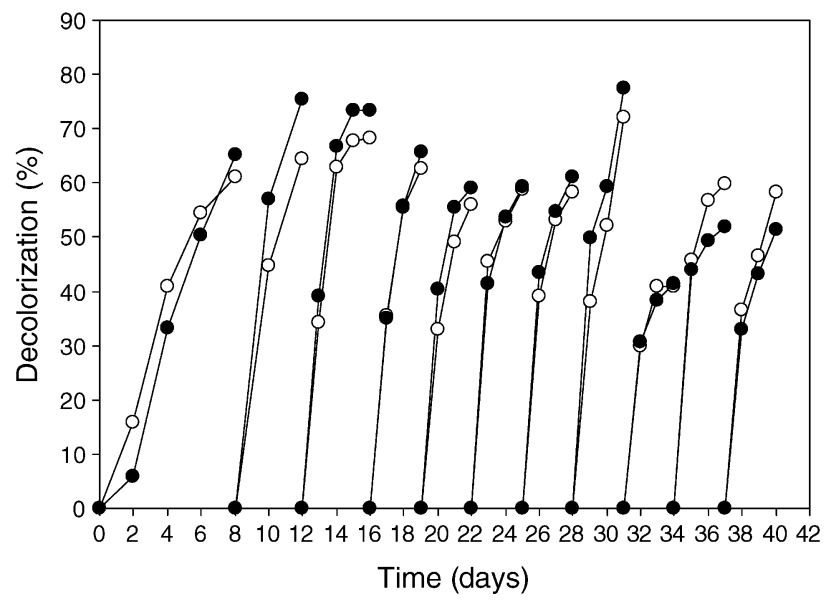

Fig. 1. Repeated-batch decolourization tests using $P$. chrysosporium immobilized in different carriers materials: polyurethane foam (O) and scouring web $(\bigcirc)$.

Cultures immobilized on PUF or SW behaved similarly, as can be seen in Fig. 1. The time needed to obtain significant decolourization was reduced from 8 days (first batch) to 3 days (third batch). It should be stressed that fungal growth on the supports was observed during batch operation, and specially on the first one. On the third batch it is likely that the fungus had reached optimum growth, thus being more adapted to the effluent environment. Because of this adaptation and growth, the immobilized mycelia exhibited rapid decolourization, thereby reducing the processing time. Therefore, further batches were conducted for 3 days each.

During the 40 days of repeated-batch tests, average decolourization efficiencies of 62 and $60 \%$ were achieved with PUF and SW, respectively. The fungus maintained a relatively stable decolourization for a long period. The results demonstrate that $P$. chrysosporium immobilized on PUF or on SW is able to treat the effluent efficiently in a long-term operation. Polyurethane foam was selected for further studies because it is cheaper and mechanically more resistant than scouring web.

Observation from this experiment showed that the immobilized mycelia took a long time to grow in the presence of effluent before acclimating to the effluent environment. This suggested that the fungus should be incubated in an appropriate growth medium without effluent before starting the decolourization phase. This would reduce the lag time in the decolourization process. Incubation of fungus on growth medium without effluent allows the immobilization on the support and growth to an optimum level before being used for decolourization. Therefore, in the remaining studies $P$. chrysosporium was previously grown in growth medium without effluent.

\subsection{Optimization of the decolourization medium composition}

Many studies concerning effluent decolourization with white-rot fungi use media containing Tween 80, thiamine and nitrogen $(0.6 \mathrm{mM})$, alone or in combination [17-20]. However, it is not economically feasible to add such expensive components to treat wastewater. In order to reduce, as much as possible, the addition of such chemicals to the effluent, the decolourization performance of $P$. chrysosporium was studied in the presence and absence of Tween 80, thiamine and nitrogen, throughout nine repeated-batch tests. Addition of Tween 80 did not improve the decolourization ability of $P$. chrysosporium. The decolourization was not affected when thiamine or exogenous nitrogen were removed from basal medium neither when both thiamine and nitrogen were removed. In fact, similar decolourization efficiencies (54-59\%) were found among the different combinations of medium components tested.

Literature refers that white rot fungi require an additional carbon source (usually glucose) for efficient decolourization [21], although variable glucose concentrations for maximum decolourization have been reported [20,22,23]. In order to minimize the glucose concentration in the decolourization medium, the decolourization performance at 0,2 , 3,4 and $5 \mathrm{~g} / \mathrm{l}$ glucose was investigated. Five repeated decolourization batches were conducted for each concentration, each batch lasting for 3 days. In the first batch, the decolourization ability in all tested media was very similar (ca. 56\%) irrespective of glucose concentration (Fig. 2). This was probably due to some glucose storage inside the cells, since cultures were originally grown at $10 \mathrm{~g} / \mathrm{l}$. For 0 and $2 \mathrm{~g} / \mathrm{l}$ of glucose the decolourization ability was initially good (first batch) but decreased to quite low levels in the second and following batches (Fig. 2). The decolourization ability throughout the five batches was higher and more stable at $5 \mathrm{~g} / \mathrm{l}(56 \%)$ than at $3 \mathrm{~g} / \mathrm{l}(46 \%)$ and $4 \mathrm{~g} / 1$ $(46 \%)$. Within the range studied the optimum concentration of glucose was $5 \mathrm{~g} / \mathrm{l}$. Accordingly, the glucose content of the decolourization basal medium should be $5 \mathrm{~g} / \mathrm{l}$. Similarly, Kapdan and Kargi [20] observed that the minimum glucose concentration for efficient decolourization of a textile dyestuff by $C$. versicolor in an $\mathrm{RBC}$ reactor, was $5 \mathrm{~g} / \mathrm{l}$.

\subsection{Continuous effluent treatment in $R B C$ reactor}

A rotating biological contactor (RBC) containing $P$. chrysosporium immobilized on PUF disks was operated with optimized decolourization medium (basal medium without both thiamine and exogenous nitrogen) in continuous mode with a residence time of 3 days.

The $\mathrm{RBC}$ reactor was monitored to determine the active life of the biocatalyst (Fig. 3). During the initial 17 days an average decolourization of $54 \%$ and an average total phenols reduction of $62 \%$ were observed. From the 17 th day of continuous operation, a progressive decrease in colour removal was observed while the reduction of total phenols was reasonably stable. Minimum values of 27 and $56 \%$ were recorded on the 24th day, for colour and total phenols reduction, respectively. During the course of continuous 


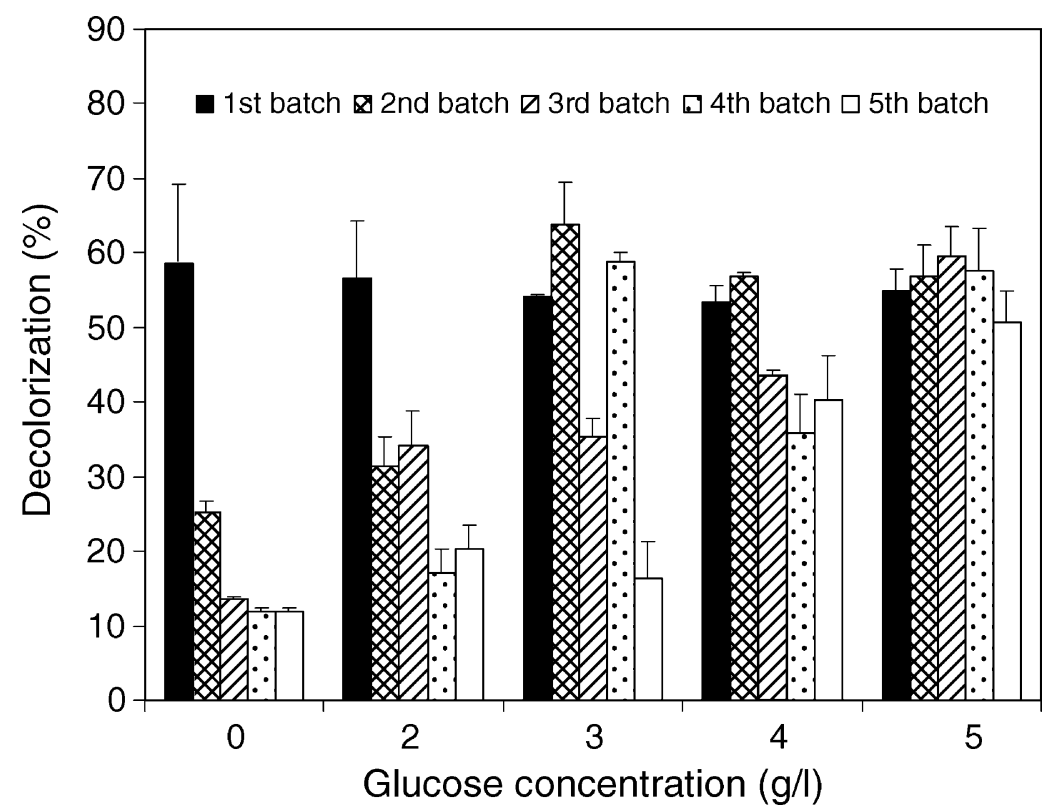

Fig. 2. Effect of glucose concentration on the effluent decolourization by $P$. chrysosporium immobilized on polyurethane foam in repeated-batch tests (each batch was conducted for 3 days). Decolourization medium without addition of both thiamine and nitrogen was used in these experiments. Values are means of three replicates \pm S.D.

decolourization it was observed that the biofilm thickness in the first stage of the reactor increased more than in the remaining stages. The first stage was constantly exposed to the nutrient containing decolourization medium. Samples were taken from the three stages of the reactor, on days 9 and 19 of operation, for colour measurement. It was observed that, from days 9 to 19 , the amount of colour removed, decreased by $58 \%$ in the first stage and by $23 \%$ in the second stage and no significant decrease occurred in the third stage. Therefore, the decrease in efficiency with the increase in the treatment period recorded was probably due to the loss of

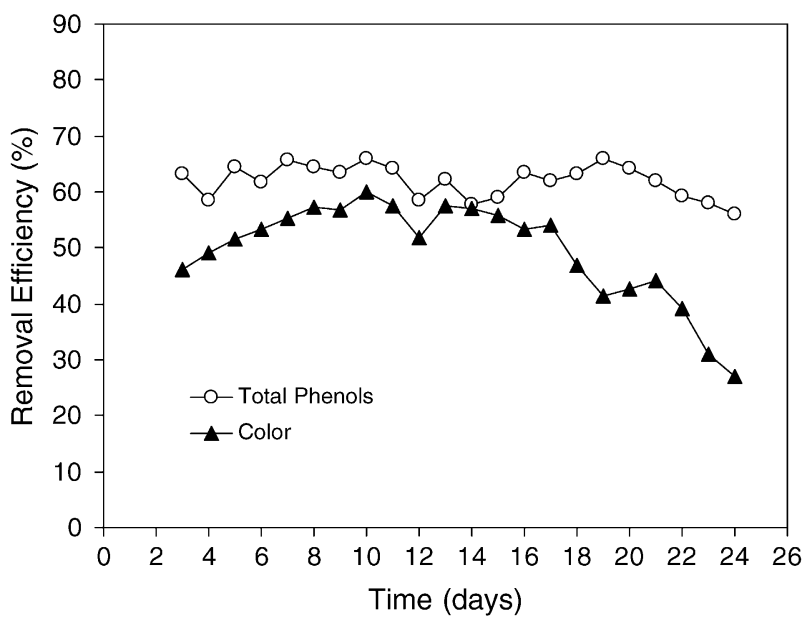

Fig. 3. Colour and total phenols removal performance of continuous RBC reactor operated in one way feeding mode. Decolourization medium without addition of both thiamine and nitrogen was used in these experiments. mycelial activity, primarily in the first stage, caused by diffusion limitations.

A similar continuous decrease in colour reduction of a bleach plant effluent after the 17th day of operation in RBC containing $P$. chrysosporium was observed by Yin et al. [17]. Kapdan and Kargi [20] also reported a decrease in the textile dye decolourization efficiency with time, in repeated-batch operation of RBC with C. versicolor. In both studies the decrease in activity was attributed to diffusion problems caused by excessive mycelial growth.

A second attempt was made to avoid the excessive growth in the first stage of the reactor. The reactor was operated as follows: during the first 17 days the effluent was fed in the same way as previously. After day 17 the feed was reversed, i.e. the feed inlet was in the third stage, with the outlet being now in what was initially the first stage. In the initial 17 days the results were comparable to the ones obtained in the first run (Fig. 4). After feed reversal, the activity was re-established after 3 days and an average decolourization of $53 \%$ and an average total phenols reduction of $62 \%$ were achieved in the following 16 days, i.e. until day 36 (Fig. 4). There was a significant decrease in the reactor efficiency after that period, probably due to an excessive biomass growth in all stages. The excess of mycelia could, in principle, be removed by scraping the surface of the disks and probably the decolourization ability could be recovered, thus increasing the operation period of the reactor. However, this was not performed because it was not possible to open the reactor during the operation.

The reactor with one way feeding (first run, Fig. 3) was only able to operate for 17 days without clogging prob- 


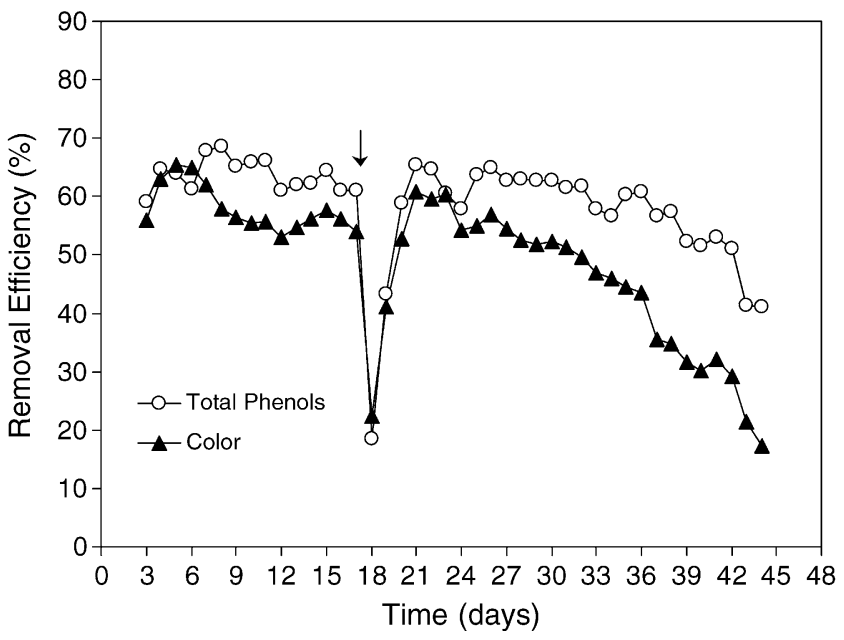

Fig. 4. Colour and total phenols removal performance of continuous RBC reactor operated in alternated feeding mode. Arrow signs the inversion of reactor feeding. Decolourization medium without addition of both thiamine and nitrogen was used in these experiments.

lems, whereas the reactor with alternated feeding (second run, Fig. 4) was operated twice as long, maintaining at least $50 \%$ average colour removal. Thus, it was possible to double the active fungal lifetime, with colour and total phenols being reduced, on average, by 55 and $63 \%$, respectively. At the same time, $48 \%$ of COD in the initial wastewater was metabolized.

Ohmomo et al. [10] reported the continuous decolourization of molasses wastewater in a bubbling column reactor with $C$. versicolor immobilized within Ca-alginate gel. With such a system an almost constant decolourization yield of $66 \%$ and a COD reduction of $46 \%$ were obtained during 16 days operation. In the continuous system described here, a slightly lower decolourization was obtained but the reduction of COD was similar, during 36 days operation. Although the alginate immobilized system was adequate for laboratory scale studies, it may not be attractive for large-scale applications. Drawbacks of the alginate system include (1) associated diffusional limitations that result in the localization of mycelia to a limited thickness near the outer surface of the alginate bead and (2) the susceptibility of calcium alginate to degradation [23]. The system described here seems to be more convenient for industrial application due to the special characteristics of RBC.

Recently, Fujita et al. [8] studied the decolourization of melanoidin present in a synthetic effluent, using a bioreactor with $C$. hirsutus immobilized onto polyurethane foam cubes combined with an ultramembrane filtration unit. The contribution of the fungal bioreactor alone to the decolourization was only $45 \%$, in a sequencing batch operation for 10 days. It may be concluded that higher decolourization efficiency was obtained in the continuous RBC here described, together with a longer operation time (36 days).

\section{Conclusions}

Results of the present investigation reveal that it is possible to treat the sugar refinery effluent continuously in a rotating biological contactor with $P$. chrysosporium immobilized on polyurethane foam disks and that the active fungal lifetime can be increased by simply reversing the feed inlet of the reactor.

This system not only removed the colour of the effluent by $55 \%$ but also reduced total phenols and COD by 63 and $48 \%$, respectively, suggesting its potential use in bioremediation of effluents.

\section{Acknowledgements}

The authors would like to thank PEDIP program (Portugal) for the financial support through the Project EUREKA EUROAGRI 1974 RESINAS.

\section{References}

[1] Bento LSM, Correia C. Regeneration of a styrenic divinylbenzenic strong base resin for sugar decolourisation with calcium chloride in a calcium saccharate solution. In: Greig JA, editor. Proceedings of the Ion Exchange at the Millenium (IEX 2000). Cambridge: Imperial College Press, 2000. p. 298-305.

[2] Guimarães C, Bento LSM, Mota M. A study of sugar colourants through ion exchange and salt regeneration. Int Sugar J 1996;98:584 7.

[3] Aoshima I, Tozawa Y, Ohmomo S, Ueda K. Production of decolorizing activity for molasses pigment by Coriolus versicolor Ps4a. Agric Biol Chem 1985;49:2041-5.

[4] Nahle C. Biological purification of sugar factory waste water (beet and cane). In: van der Poel PW, Schiweck H, Schwartz T, editors. Sugar technology-beet and cane sugar manufacture. Berlin: Verlag Dr. Albert Bartens KG, 1998. p. 1008-18.

[5] Migo VP, Matsumura M, Delrosario EJ, Kataoka H. Decolorization of molasses wastewater using an inorganic flocculent. J Ferment Bioeng 1993;75:438-42.

[6] Watanabe Y, Sugi R, Tanaka Y, Hayashida S. Enzymatic decolorization of melanoidin by Coriolus sp. No. 20. Agric Biol Chem 1982;46:1623-30.

[7] Kumar V, Wati L, Nigam P, Banat IM, Yadav BS, Singh D, et al. Decolorization and biodegradation of anaerobically digested sugarcane molasses spent wash effluent from biomethanation plants by white-rot fungi. Process Biochem 1998;33:83-8.

[8] Fujita M, Era A, Ike M, Soda S, Miyata N, Hirao T. Decolorization of heat-treatment liquor of waste sludge by a bioreactor using polyurethane foam-immobilized white rot fungus equipped with an ultramembrane filtration unit. J Biosci Bioeng 2000;90:387-94.

[9] Guimarães C, Bento LSM, Mota M. Biodegradation of colorants in refinery effluents-potential use of the fungus Phanerochaete chrysosporium. Int Sugar J 1999;101:246-51.

[10] Ohmomo S, Itoh N, Watanabe Y, Kaneko Y, Tozawa Y, Ueda K. Continuous decolorization of molasses waste water with mycelia of Coriolus versicolor Ps4a. Agric Biol Chem 1985;49:2551-5.

[11] Antonie RL. Fixed biological surfaces-wastewater treatment: the rotating biological contactor. Boca Raton, FL: CRC Press, 1976.

[12] Tyagi RD, Tran FT, Chowdhury AKMM. Biodegradation of petroleum refinery wastewater in a modified rotating biological contactor 
with polyurethane foam attached to the disks. Water Res 1993;27:919.

[13] Tien M, Kirk TK. Lignin peroxidase of Phanerochaete chrysosporium. Meth Enzymol 1988;161:238-49.

[14] Singleton VL, Rossi A. Colorimetry of total phenolics with phosphomolybdic-phosphotungstic acid reagents. Am J Enol Vitic 1965;16:144-58.

[15] APHA standard methods for examination of water and wastewater. 17th ed. Washington, DC: APHA, 1989.

[16] Guimarães C, Matos C, Azeredo J, Mota M, Oliveira R. The importance of the morphology and hydrophobicity of different carriers on the immobilization and sugar refinery effluent degradation activity of Phanerochaete chrysosporium. Biotechnol Lett 2002;24:795-800.

[17] Yin C-F, Joyce TW, Chang HM. Kinetics of bleach effluent decolorization by Phanerochaete chrysosporium. J Biotechnol 1989;10:6776.
[18] Prouty AL. Bench-scale development and evaluation of a fungal bioreactor for color removal from bleach effluents. Appl Microbiol Biotechnol 1990;32:490-3.

[19] Cammarota MC, Sant'Anna Jr GL. Decolorization of Kraft bleach plant E1 stage effluent in a fungal bioreactor. Environ Technol 1992;13:65-71.

[20] Kapdan IK, Kargi F. Biological decolorization of textile dyestuff containing wastewater by Coriolus versicolor in a rotating biological contactor. Enzyme Microb Technol 2002;30:195-9.

[21] Eaton D, Chang HM, Kirk TK. Fungal decolorization of Kraft bleach plant effluent. Tappi J 1980;63:103-6.

[22] Yin C-F, Joyce TW, Chang HM. Role of glucose in fungal decolorization of wood pulp bleaching effluents. J Biotechnol 1989;10:77-84.

[23] Pallerla S, Chambers RP. New urethane prepolymer immobilized fungal bioreactor for decolorization and dechlorination of Kraft bleach effluents. Tappi J 1996;79:155-61. 